\title{
The Pedagogical Knowledge Deployed by a Primary Mathematics Teacher Educator in Teaching Symmetry
}

\author{
Ma Isabel Pascual *, Miguel Montes (D) and Luis Carlos Contreras (D) \\ Research Center COIDESO, University of Huelva, 21007 Huelva, Spain; miguel.montes@ddcc.uhu.es (M.M.); \\ lcarlos@uhu.es (L.C.C.) \\ * Correspondence: isabel.pascual@ddcc.uhu.es
}

check for updates

Citation: Pascual, M.I.; Montes, M.; Contreras, L.C. The Pedagogical Knowledge Deployed by a Primary Mathematics Teacher Educator in Teaching Symmetry. Mathematics 2021, 9, 1241. https://doi.org/ $10.3390 /$ math 9111241

Academic Editor: Michael Voskoglou

Received: 20 April 2021

Accepted: 25 May 2021

Published: 28 May 2021

Publisher's Note: MDPI stays neutral with regard to jurisdictional claims in published maps and institutional affiliations.

Copyright: (c) 2021 by the authors. Licensee MDPI, Basel, Switzerland. This article is an open access article distributed under the terms and conditions of the Creative Commons Attribution (CC BY) license (https:// creativecommons.org/licenses/by/ $4.0 /)$.

\begin{abstract}
Although the knowledge required by mathematics teacher educators is a relatively recent area of research, there has been significant progress in the field over the last few years. The classic distinction of a teacher's knowledge into content knowledge and pedagogical content knowledge prompts us to reflect in this regard on what should constitute the content of primary teacher education programmes, and how the educator might mediate this content to make it accessible to their prospective teachers. This paper aims to contribute to this progress through a study into the work of Lucas, a teacher educator, during the course of a training session with prospective primary teachers. Critical observation of the video recording brought to the fore salient teaching situations on the topic of symmetry, which led us to explore the pedagogical content knowledge deployed in the session through a guided interview with the educator. Analysis of extracts from this interview enabled us to identify three main categories of this PCK: knowledge about how to teach programme content; knowledge about the characteristics of prospective primary teachers' learning; and knowledge about the standards and norms of primary teacher education programmes.
\end{abstract}

Keywords: primary mathematics teacher educator knowledge; pedagogical content knowledge in teacher education; primary teacher education; symmetry

\section{Introduction}

Despite recent advances in research into the knowledge of mathematics teacher educators, there is little consensus about what kind of knowledge is appropriate to the profession [1]. One starting point for taking up the challenge of characterising the knowledge of primary teacher educators (PTEs) has been to approach it in terms of the distinction between content knowledge and pedagogical content knowledge [2-4], which has characterised the study of mathematics teachers' knowledge [5-9]. However, there are three aspects of the context in which PTEs work that highlight substantive differences between their professional knowledge and that of mathematics teachers $[4,10]$ : content, student profile, and teaching objectives. In terms of content, teacher education goes beyond the purely mathematical; regarding the student profile, the prospective primary teachers (PPTs) are adults; and with respect to teaching objectives, the goal is teaching to teach [4].

On the assumption that teacher education as a whole encapsulates and exceeds purely mathematical content, it is pertinent to ask what should comprise the content of primary teacher education. There is a well-established body of research literature into mathematics teachers' knowledge [5-9], and this offers some indication, at least from a cognitive perspective, as to what this content should be, drawing on the utility of the different models for structuring primary teacher education [11]. The first consequence of adopting such an approach is the need to establish the correlation between the different kinds of knowledge required by a mathematics teacher and a mathematics educator. From one perspective, there are studies that indicate that there is a common framework of knowledge shared by teachers and educators, while at the same time recognising other areas of expertise 
peculiar to each. In this regard, there are elements of the educator's knowledge that are not considered necessary for a teacher to know, and vice versa [12,13]. Alternatively, the teacher's knowledge can be considered as subsumed within the educator's knowledge, albeit each nuanced in terms of their particular purposes and utility [4]. From this perspective, the difference lies in the observation that while the teacher uses this knowledge as a tool, largely implicitly, in planning their mathematics teaching, the educator is required to have the ability to mediate this same knowledge in such a way as to facilitate its construction within the minds of the prospective teachers. In this view, it is assumed that the educator has a deeper, more extensive knowledge of mathematics teaching than the teacher [4]. More specifically, the range of the educator's knowledge can be characterised by a network of interconnections between the different knowledge domains involved in teaching, as well as other aspects of teacher development. In sum, the mathematical foundations on which the educator's knowledge rests are considered to be more extensive than those of the mathematics teacher. Our position concurs with this view insofar as professional knowledge is concerned. At the same time, we recognise a division of teacher education content into three large domains: professional knowledge, teaching practices, and professional identity [14]. The role of the educator within this conceptualisation is to enable the prospective teachers "... to think like a teacher, ... to know like a teacher, ... to feel like a teacher and ... to act like a teacher" [15] (p. 698). These four aspects require different kinds of knowledge on the part of the educator. The educator's knowledge involved in the tandem "to think like a teacher" and "to know like a teacher" can usefully be explored in specific models of teachers' knowledge (e.g., MTSK [7]), yet the question remains about which elements of the educator's knowledge are deployed in teaching PPTs "to feel like a teacher" and "to act like a teacher". Evidence of these facets of the teacher education programme content, structured as in Figure 1, can be consulted in previous studies by the authors [16].

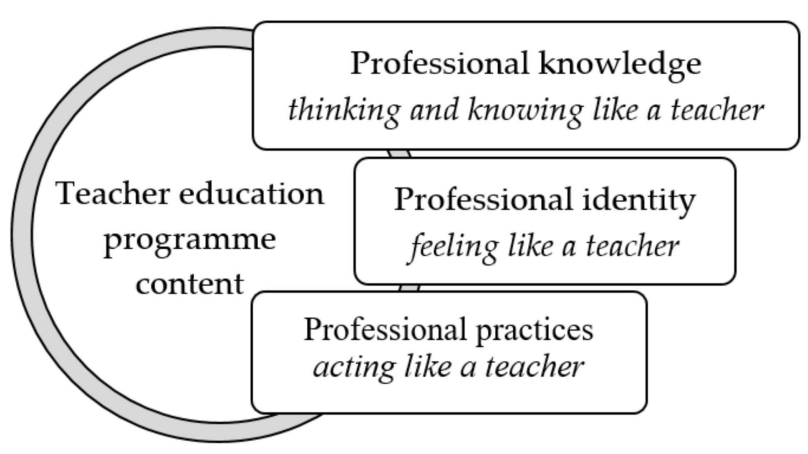

Figure 1. Content of initial mathematics teacher education.

Consistent with the foregoing review of research into the content of initial teacher education and the nature of the educator's knowledge of this content, in this study we focus on answering the question: which indicators of pedagogical content knowledge can be identified in the course of a class on symmetry with a group of PPTs? The aim of the study is to explore the knowledge that enables the educator to deal with a previously studied content item, and so provide evidence for a range of elements that we consider to constitute his pedagogical knowledge. In order to do this, we conducted an interview with the educator about an observed session he had delivered as part of an initial primary teacher education course. Excerpts from the interview, illustrative of certain types of knowledge, were then analysed and assigned to categories following a top-down and bottom-up methodology [17].

\section{The Pedagogical Knowledge of Primary Teacher Educator}

In this section, we discuss the professional knowledge involved when educators guide PPTs to construct their own knowledge. Our discussion covers the three areas of 
content into which initial primary teacher education can be divided. In this regard, the critical studies are once again those that found parallels between the work of teachers and educators $[2,3,12,18]$. Some studies, adapting the notion of the teaching triangle [18], reassign the vertices of the teacher-teaching-student triangle according to the actors in initial teacher education programmes. Thus, the adapted version places teacher education content (the mathematical and didactical elements to be learned by prospective teachers) at the vertex previously occupied by knowledge of the subject to be taught in the original version of the triangle, as illustrated in Figure 2. Hence, the educator would be in the vertex assigned to "teacher" in the usual teaching triad, and the prospective teacher the vertex assigned to the learner.

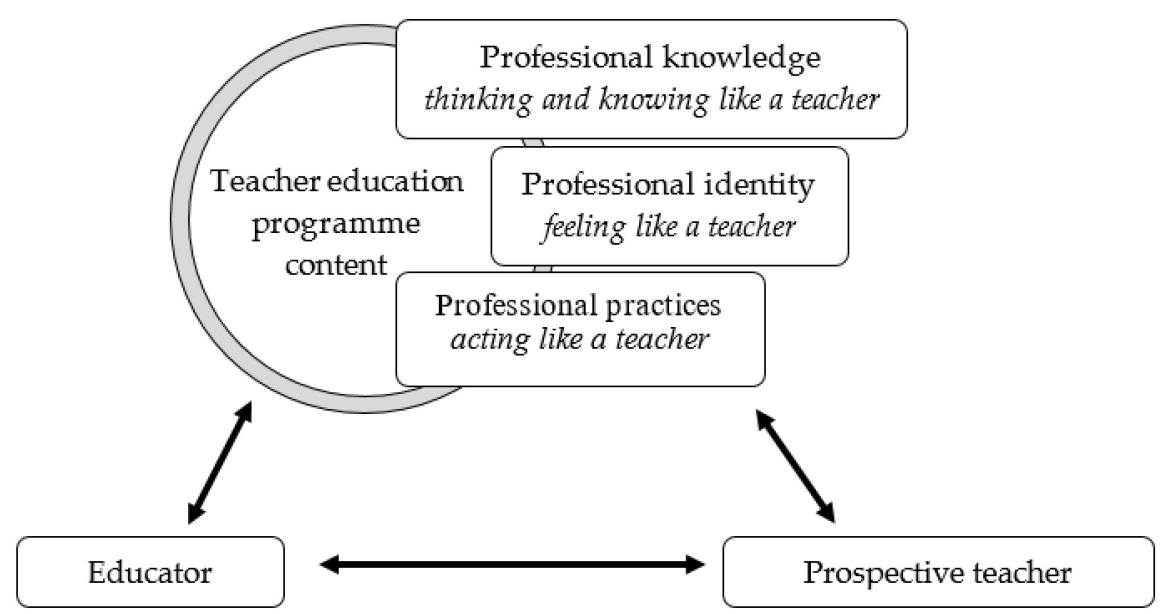

Figure 2. The teaching triangle in initial teacher education.

A recurrent observation of the research literature into PTEs' knowledge [12] concerns the dual focus of their discourse. At one level, the discourse mirrors that of teacher and student, whereby content and its associated pedagogical considerations are developed. At the same time, there is another level in which the discourse reflects the relationships between the PPTs and their future students, and that generates a set of different pedagogical-mathematical considerations. In effect, the PPTs take on a dual role, as learners and future teachers.

In addition to insights into these two interrelated teaching planes, another major contribution of previous studies concerning PTEs' professional knowledge [19], is the extension of the tools used for analysing teachers' pedagogical content knowledge (PCK) [2]. Traditionally, PCK has been conceptualised as comprising knowledge about the students, teaching, and the curriculum [5-9]. Translated to this new scenario, the PCK corresponding to PTEs has been adapted to include categories such as knowledge about how PPTs learn, knowledge of how to teach the content pertaining to the teacher education course, and knowledge of the norms and standards governing primary teacher education programmes [19], as summarised in Figure 3 below.

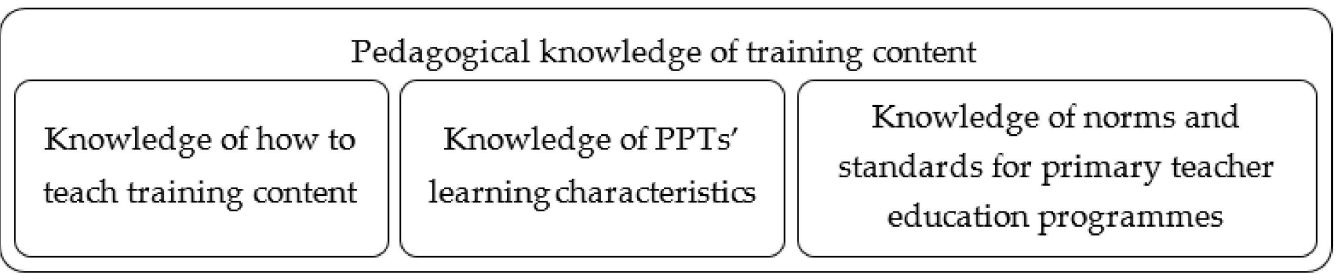

Figure 3. Structure of teacher educators' pedagogical knowledge.

Combining these two research strands, we note that, for example, PTEs' knowledge about the PPTs' learning characteristics bifurcates into PTEs' knowledge of PPTs' capacities 
for learning mathematics and PTEs' knowledge of trainees' learning potential. In this respect, the prospective teachers need to rethink the mathematics they have previously learned, which can lack depth and be somewhat fragmentary [20], so as to achieve a deeper understanding of essential mathematics [21] that will allow them to transform it (the maths) so that it can be learned by their future pupils. Likewise, the educator's knowledge of how to teach the training content should not only enable them to promote in their trainees the construction of professional knowledge, but also help them in the development of professional abilities and the construction of a professional identity [19]. Finally, knowledge about standards in teacher education programmes can enable the educator to establish connections between elements learned from different courses, and help the educator to generate learning and professional development sequences for the prospective teachers.

\section{Methodological Design}

Primary teacher training programmes consist of a heterogeneous body of knowledge. The professional backgrounds of the educators delivering the programmes are no less heterogeneous [22], nor their beliefs regarding how such programmes should be constituted [23]. This inherent idiosyncrasy makes case study methodology an appropriate choice of research approach. Assuming the potential of instrumental case study for generating theoretical elements [24-26], and in particular to contribute to the generation of theory about professional knowledge $[2,4,7,8,16,20]$, we followed that research design. Hence, we adopted the top-down and bottom-up [17] focus usually used in this kind of research design, which would enable us to achieve a snapshot of an actual teacher education programme in the process of constructing professional knowledge [17].

\subsection{Context of the Research}

The subject of this study, who for the purposes of this paper will be referred to as Lucas, was a primary mathematics teacher educator with close to 40 years' experience, and an active researcher into mathematics education in the field of teacher knowledge and professional development. Given his career trajectory, experience, and wealth of knowledge, Lucas was an especially rich source of information, which was the reason he was selected for the study, in addition to the question of accessibility of information. Although not the main focus of the study, understanding the educator's knowledge requires taking into account their conceptions about the programme content and the teaching-learning processes involved. The role of conceptions in professional knowledge has been addressed in previous studies into teacher knowledge [7], and consistent with these, we believe that they interact with the subdomains making up the educator's knowledge. In this regard, Lucas's conceptions about primary education were reflected in his concern to go beyond the purely mathematical in his training sessions and promote a broader notion of professional knowledge.

Although various models of primary teacher education are available, in this study we characterised the content of teacher education according to the model followed in the context of this research. At the University of Huelva, where the research took place, the programme content for initial primary teacher training is closely related to the foundations of the Mathematics Teachers' Specialised Knowledge (MTSK) model [7]. The focus is chiefly on cognitive elements of both mathematical and pedagogical knowledge, as recognised by the MTSK model. Twenty-one of the 240 ECTS credits constituting the degree in primary education are dedicated to mathematics teaching, distributed across different courses and oriented around distinct areas of mathematics. The excerpts providing evidence of knowledge that were included in this study were extracted from the observation of a class on teaching symmetry and from a follow-up interview, the latter forming the chief source. The specific course in question was a semester-length course in the final year, focusing on geometry. It included content relating to flat shapes, three-dimensional bodies, and isometry in the plane. This was complemented by other material on the use of teaching aids, PPTs' analysis of conceptions, and their awareness of the difficulties that primary pupils 
might face at this stage of their mathematical development. Among the aids, the educator particularly focused on the Geogebra software, a tool for representing and reflecting on geometry.

\subsection{Data Collection and Analysis}

Two complementary data sources were selected for this study. First, a training session on symmetry was recorded and transcribed. Episodes from the session were labelled

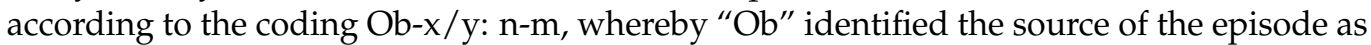
the observation, " $\mathrm{x} / \mathrm{y}$ " gave the day and month of the recording, and " $\mathrm{n}-\mathrm{m}$ " referred to the corresponding line numbers of the transcription. Field notes were also made during the sessions by the lead author, acting as a nonparticipating observer [27]. Second, the data collected directly from the session were complemented with a follow-up interview with Lucas, as a means of corroborating indicators captured in the recording and validating the results. This secondary source followed the coding Int-S: n-m, whereby "Int-S" identified the source as the interview, and " $n-m$ " referred to the corresponding line numbers in the transcription, as in the case of the observation above.

For analysing the data, episodes were selected from one or other of the sources, and grouped according to the content item involved, so as to create categories that would enable us to understand what was being worked on in the training session, and what professional knowledge was underlying the planning and management of these situations. Validation of the analysis involved a process of triangulation through expert consensus [27], and by contrasting excerpts from the different data collection instruments, in a multimethodological approach [28].

\section{Analysis}

Extracts from the transcriptions of the observation and interview are included below to provide evidence that characterised both the primary education course content and the pedagogical knowledge of the educator.

The focus of the observed session was the topic of symmetry, on which Lucas worked with the aid of the Geogebra tool. In excerpt Ob-11/10:769-780, when the PPTs were working at individual computers, Lucas asked a student to share her work on the projector screen for everybody to see.

Lucas: OK, so we're all going to draw a polygon of any kind in Geogebra, without the grid and without axes. Draw it yourselves using the polygon option. [...] It's curious, we always tend to draw one of the sides parallel to one of the axes. Now the axis of symmetry shouldn't be parallel to this side, and it shouldn't be parallel to the base either ... not to this side or the base.

PPS: A straight line?

Lucas: Yes, a straight line. Good, we need another point. No, further down. ... OK [The shared screen shows the following:]

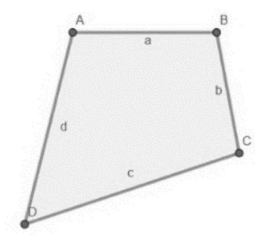

Excerpt Ob-11/10:769-780. Construction of the task in Geogebra.

Lucas's instructions focused on the position of the axis of symmetry relative to the shape. He consistently underlined that the alineation of the figure should not coincide 
with the edges formed by the natural borders of whatever resource is being used, which despite not necessarily being Cartesian, might nevertheless be suggestive of parallelism and horizontality. When asked about his insistence on this, Lucas explained it in excerpts Int-S:167-169 and Int-S:175-178.

Lucas: The thing about the axis [of symmetry] not being vertical or horizontal, especially it not being vertical—the standard way of representing symmetry-is really hard for them to grasp.

Excerpt Int-S:167-169—PPTs' difficulties with positioning of polygons.

Lucas: Some of the problems which emerge in teacher education are the result poor learning when the trainees were at primary school themselves, and they bring with them to the teacher education course a lot of incorrect notions and concepts they picked up then.

Excerpt Int-S:175-178—origin of PPTs' difficulties with mathematics.

These excerpts illustrated Lucas' knowledge of the PPTs' grasp of the concept of symmetry. He explained that changing the position of the axes meant that one of the key properties of axial symmetry - the perpendicularity of the line segments connecting each point to its transformation-was foregrounded. The result of placing the axes in a vertical position was that the transformed shape aligned perfectly with the original, thus obscuring the requisite of perpendicularity, of which the PPTs often failed to take account. The tendency of the PPTs to construct symmetry in this way had its origin, Luca affirmed, in their mathematical experiences with the concept, resulting in a poor conceptual image of the transformation. The advantage of targeting PPTs' weak points in mathematics, he said, was the understanding they gained of the pedagogical aspects of teaching symmetry for their future work. Excerpt Int-S: 19-22 highlights this:

Lucas: By looking closely at the areas of difficulty PPTs have with symmetry, they can anticipate the kind of difficulties which primary pupils can have with symmetry and its properties.

Excerpt Int-S: 19-22-PPTs' difficulties reflecting those their future pupils.

In the extracts below, from the same class on symmetry, Lucas drew attention to the conditions that each point of symmetry must meet with respect to the original, and insisted that the symmetry must be constructed by applying the transformation, and not by using the reflection function in the Geogebra application. Lucas expanded on the use of the application as a teaching aid in the teacher education programme in excerpt Int-S: 39-51:

Lucas: Geogebra has the advantage of removing the difficulty that people can have in constructing graphical relationships, so that they can focus on the underlying mathematical relationships.

Excerpt Int-S: 39-51—advantages of using Geogebra.

Lucas cited further advantages of the application. These, although equally applicable to symmetry, referred in this case to the topic of triangles from a previous session, specifically, the benefit of visualising the implications of the angle bisector theorem for acute, right, and obtuse angles, as expressed in excerpt Int-S: 83-86:

Lucas: What Geogebra does is enable you to see in real time what happens when-in the case of triangles, for example-when a triangle is displaying certain properties, such as when an angle goes from being acute to being obtuse. Or with a rectangle, it allows you to see your conjectures about properties play out in a way which static geometry cannot match.

Excerpt Int-S: 83-86-the dynamic nature of the Geogebra software.

Other utilities of the software that Lucas aimed to transmit were, first, that Geogebra should be regarded as an aid to their mathematics teaching, as well as to their learning (excerpt Int-S: 122-125), something which the PPTs do not always taken on board; and 
second, that using it in the course of their own teaching offers distinct benefits (excerpt Int-S: 107-109).

Lucas: The problem with this resource, as with others, is that they find it difficult to shed the role of being a learner. I think that if a prospective teacher is going to take on the role of a teacher, they shouldn't still be learning whatever it is they are going to teach, they need to have moved on from there.

Excerpt Int-S: 122-125- the dual role of teaching resources in initial training.

Lucas: Yes, I do try to transmit the idea to them that Geogebra can be a really useful tool in their lessons, but it's not something I do explicitly [...] I've always believed that some kind of isomorphic process happens when you teach [...] What you do in the initial teacher education class bears a certain degree of similarity with what you'd like to see them do in their primary lessons.

Excerpt Int-S: 107-109-methodological isomorphism.

Both these extracts illustrated Lucas' knowledge of the dual role of the PPTs as both learners and future teachers, and of how pedagogical content knowledge is constructed in teacher education programmes. With regard to the first of these ideas, Lucas repeatedly recognised that the PPTs needed to develop their mathematical knowledge-an area in which primary teachers have undoubtedly been traditionally weak - at the same time that they developed their pedagogical content knowledge. This is a shortcoming that Lucas identified as one of the major difficulties of the teacher education programme, as, in his words, it is all but impossible for the PPTs to do both at once. Lucas's notion of methodological isomorphism emerged from his aim that they develop their pedagogical knowledge in terms of how Geogebra can be used in their primary lessons. Lucas's evident awareness of this process as he carried out his classes demonstrated his knowledge about how to teach PPTs to teach mathematics, and was in large part predicated on his demonstrating, during their initial training, strategies that they could subsequently replicate. Likewise, when Lucas talked about how the PPTs could use the software with their primary students, it underlined his knowledge of applications designed for teaching at this level.

As the class on symmetry continued, the PPTs displayed difficulties not only with using the teaching resource itself, but also with the properties of symmetry. This situation led Lucas to go through, step by step, the symmetric point of one of the points of the polygon with respect to the established axis of symmetry (as can be seen in the diagram in extract Ob-11/10:769-780 above). As he did so, he interpreted the sequence of instructions for using Geogebra in terms of the properties of symmetry these represented, and that they had previously worked on in class.

Lucas: I'm going to go step by step ... I know that the symmetric point of B is on a line going through $B$ which is perpendicular to the axis. So I tell the programme 'perpendicular', and I put a point and a straight line ... on a straight line perpendicular to this axis with this point, but it is on this line. I know that the symmetric point of $\mathrm{A}$ is on a straight line which goes through $\mathrm{A}$ and is perpendicular to the axis [...] What else do I know? What you said, the distance to the axis is the same as this [indicates a point and its symmetric point]. The other thing I know is that the distance from this point to the perpendicular I'm preparing here is the same as the distance from here to the corresponding point. How can I work that out? How can I put the corresponding point here? What should I do? What function can I use?

PPT: The circle?

Lucas: I don't know what unit the axis is in ... 'Circle with Centre through Point', of course. The centre will be this [indicates a point, G, on the axis] and the point will be this [indicates the point, D], OK? 


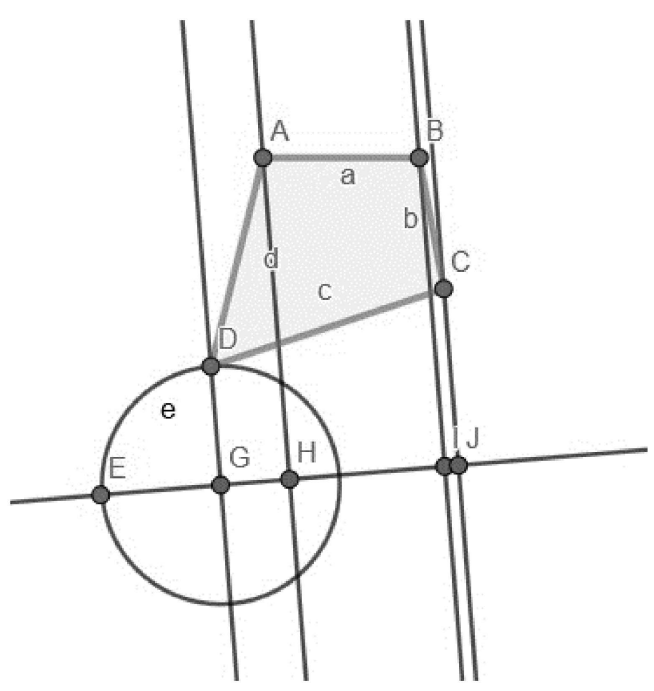

Excerpt Ob11/10: 820-844. Identifying point reflections.

In the follow-up interview, Lucas was asked about the connections between the PPTs' difficulties with the mathematical content and their pedagogical content knowledge (Excerpt Int-S: 162-164), and the design of primary teacher education programmes (Excerpt Int-S: 212-216):

Lucas: We can look at it two ways: a lack of content knowledge is a barrier to pedagogical content knowledge, and a good grounding in terms of content means you can focus your attention on the teaching-learning processes involved in this content. In my experience, that's how it is.

Excerpt Int-S: 162-164-connections between mathematical content and pedagogical content knowledge.

Lucas: The course programme, when you look at it from the outside, has a far greater load in terms of MK than PCK [...] Nevertheless, in reality the load is much more balanced, giving MK greater weight, of course.

Excerpt Int-S: 212-216-course programme structure.

The difficulties with mathematical content that Lucas observed in the PPTs here were similar to the shortcomings he had previously noted in their reflections on teaching resources. What both instances had in common is that they demonstrated that the pedagogical aspects of a concept, procedure, or resource cannot be fully contemplated until the corresponding mathematical knowledge has been properly assimilated. It is precisely this kind of knowledge - or more precisely, the lack of it - that accounted for the way the course was actually structured, something in which Lucas took an active part. As he pointed out, the prevalence of purely mathematical content over the pedagogical derived from the evident gaps in the PPTs' mathematics background. The result was a less than ideal configuration of the education programme, about which, and the various criteria necessarily applied to the choice of content, Lucas said the following:

Lucas: The first thing is that the course content gives a true reflection of what they do in primary education. The second is that the treatment I give this content must equip them to understand it in sufficient depth to be able to mediate it with their pupils. This means they need to go through a stage of unpacking. They need begin to understand the reasons why things are the way they are. [...] This process of unpacking includes coming to understand the issues of teaching and learning a concept, but understanding the concept itself and its connections is essential.

Excerpt Int-S: 194-201—criteria for selecting teacher education programme content. 
Hence, within his inventory of teacher education programme content, Lucas included not only a sound, interconnected knowledge of items on the curriculum, but also knowledge about how these can be taught, some of which will stem from a thorough understanding of the item in question, while others will be drawn from complementary pedagogical knowledge.

\section{Results}

Summarising the above, we found a range of indicators of the educator's pedagogical knowledge (Table 1). Although these were particular to the teaching session in question, they nevertheless contributed to the development of categories for structuring educators knowledge. When these elements were classified into the general categories into which we divided such knowledge, we could see three types: knowledge of how to teach programme content, knowledge of the characteristics of the PPTs' learning, and knowledge of the standards and norms of primary teacher education programmes. In the same way that the role of the PPTs shifts from learner to prospective teacher during the learning process, so the educator's considerations change from one plane to another according to the focus.

Table 1. Indicators of the educator's pedagogical knowledge.

\begin{tabular}{ccc}
\hline $\begin{array}{c}\text { Knowledge about How to } \\
\text { Teach Programme Content }\end{array}$ & $\begin{array}{c}\text { Knowledge about the Characteristics } \\
\text { of PPTs' Learning }\end{array}$ & $\begin{array}{c}\text { Knowledge about the Standards and Norms } \\
\text { of Primary Teacher Education Programmes }\end{array}$ \\
\hline $\begin{array}{c}\text { Analysis of the potential of different } \\
\text { representations of symmetry }\end{array}$ & $\begin{array}{c}\text { Foreseeing PPTs' difficulties with } \\
\text { respect to the mathematical } \\
\text { content of axial symmetry }\end{array}$ & $\begin{array}{c}\text { The contents of teacher education should start } \\
\text { from a grounded study of primary content }\end{array}$ \\
$\begin{array}{c}\text { Choice of nonstandard examples } \\
\text { regarding the relative position of shapes } \\
\text { involved in the symmetry }\end{array}$ & $\begin{array}{c}\text { Consideration of the PPTs' duality } \\
\text { as students of mathematics } \\
\text { and as future teachers }\end{array}$ & $\begin{array}{c}\text { PPT education should include elements that } \\
\text { enable the unpacking of mathematical content }\end{array}$ \\
$\begin{array}{c}\text { Reflection on PPTs' errors vis-à-vis } \\
\text { symmetry aids their understanding of } \\
\text { pedagogical aspects of their teaching } \\
\text { of symmetry hinder the } \\
\text { construction of knowledge } \\
\text { about how it might be taught }\end{array}$ & \\
\hline $\begin{array}{c}\text { Use of Geogebra and reflection about its } \\
\text { potential as a training resource with PPTs }\end{array}$ & \\
\hline $\begin{array}{c}\text { The possibility of methodological } \\
\text { transference from teacher training to } \\
\text { primary education }\end{array}$ & \\
(methodological isomorphism) & & \\
\hline
\end{tabular}

In the category concerning knowledge about how to teach programme content, the first two indicators-"analysis of the potential of different representations of symmetry" and (especially) "choice of nonstandard examples"-were representative of the subcategory "examples for teacher education". Lucas chose these examples in order to encourage his students to reflect on how their own efforts at constructing an understanding of symmetry can foreground both the challenges the topic presents to their future pupils and a means of tackling these. The aim of the task, with its corresponding examples, was twofold. In addition to developing the PPTs' mathematical skills, Lucas aimed to provide a useable model of primary teaching. Lucas's notion of methodological isomorphism, displayed over the duration of the course, illustrated his knowledge of strategies for teacher education at the same time that it showed his knowledge of primary teaching techniques. These examples once again highlighted the two levels at which the educator's discourse operated. Within his knowledge about how to deliver the programme content, there could be distinguished decisions oriented towards the (re)construction of mathematical content and those aimed at the construction of pedagogical content knowledge. Regarding the former, we can note the proximity of his approach to the way a mathematics teacher might construct knowledge with their students, an approach accounted for by the gaps in the 
PPTs' mathematical knowledge (something of which Lucas was aware). Nevertheless, it is not solely mathematical knowledge that is the focus of the teacher education course. The PPTs also learn to act as teachers, an end that is achieved, as Lucas affirmed, principally through the strategy of providing PPTs with a template of good practice to follow.

We also found evidence of areas of difficulty that were identified by Lucas among the PPTs, chiefly with respect to mathematical knowledge. Awareness of this kind of lack of knowledge among the PPTs by the educator is taken into account by a set of indicators within the category of characteristics of the PPTs' learning. In addition to the examples of these difficulties that Lucas noted, it is important to highlight the connections he made between the PPTs' mathematical knowledge and the pedagogical knowledge that they need to acquire. Here, the dual role of the PPTs was decisive in terms of their interaction with the programme content. Over the course of the session, the focus on mathematical and pedagogical-mathematical knowledge alternated, but progress was conditioned insofar as PPTs' incomplete knowledge of the former could act as a barrier to their development in the latter.

Finally, Lucas's affirmations also provide evidence of his awareness of the standards and norms that frame primary teacher education programmes, making an explicit link between training content and the primary curriculum. In the context of widely varying perspectives on how teacher education should be constituted, Lucas-responsible for course programming - affirmed that these should be primarily driven by the demands of primary education. His view was founded on the idea of the fundamental knowledge [21] that teachers must have about the subject they teach in order to make sense of the connections between contents in the education programme. The focus on purely mathematical content was complemented by pedagogical-mathematical considerations aimed at enabling the PPTs to make appropriate teaching decisions. This in turn told us something about the criteria used for selecting content, and about the learning expected of the PPTs during the teacher education programme.

\section{Discussion}

With the theoretical sensitivity given by the literature review about mathematics teacher educators' knowledge, in this work we focused on finding empirical evidence of some indicators of mathematics teacher educators' pedagogical content knowledge. Based on the analysis of the classroom practice and the interview, we found examples of pedagogical content knowledge, such as consideration of the advantages and disadvantages of using a particular teaching resource. The educator's evaluation of this resource-used as more than a teaching aid for the PPTs - and the comparison he makes of it with other resources, illustrates the difference between his knowledge and that of a teacher [2]. Consciously, the educator acts as model to be imitated by the PPTs. He assumes that his discourse and acts have to be coherent, and through that didactic isomorphism shows a way of teaching mathematics while he fosters the reconstruction of the mathematical elements that he identifies as weak in the PPT's mathematical knowledge. Thus, he shows knowledge of strategies to foster the construction of knowledge of mathematics teaching, at the same time he tries to shape the future teaching practices of the PPTs. The teacher educator carries to their students from their role as learners of mathematical content, to their future role as teachers. This empowerment is promoted by fostering a deep reflection about the nature of the mathematical content he teaches, and about the learning difficulties and teaching strategies concerning that content [29]. Thinking in a possible implication of this in teacher education programmes, it could be interesting to foster this kind of practice by teacher educators. With respect to studies aimed at drawing parallels between the way in which teachers' and educators' PCK is structured [2] (content here understood to encompass mathematical and pedagogical mathematical knowledge), our results indicated a strong similarity between the difficulties encountered by PPTs and those exhibited by primary pupils, and between the use of resources in the two contexts. Finally, we assume that further research is needed concerning PTE's knowledge, both pedagogical content knowledge 
and content knowledge, in order to gather more empirical evidence of a set of theoretical indicators that were not addressed here. This could be done through other instrumental case studies with PTEs different than Lucas, contributing to a triangulation of interstudies, taking into account the heterogeneity of the backgrounds of PTEs. This further research could also be interesting to compare the knowledge of two PTEs that teach in different teacher education programs, aiming toward a further possible generalization.

Author Contributions: Conceptualization, M.I.P.; M.M. and L.C.C.; methodology, M.I.P.; M.M. and L.C.C.; validation, M.I.P.; M.M. and L.C.C.; writing, M.I.P.; M.M. and L.C.C.; All authors have read and agreed to the published version of the manuscript.

Funding: This research was financed by the COIDESO research centre at the University of Huelva, the Ministry of Science, Innovation and Universities of the Government of Spain (project: RTI2018096547-B-I00), and the research group DESYM (HUM-168).

Institutional Review Board Statement: This study was conducted following the ethical guidelines stated by the Research centre COIDESO.

Informed Consent Statement: Informed consent was obtained from all subjects involved in the study.

Data Availability Statement: The data supporting reported results are not public, following the Spanish Law of data protection.

Conflicts of Interest: The authors declare no conflict of interest. The funders had no role in the design of the study; in the collection, analyses, or interpretation of data; in the writing of the manuscript; or in the decision to publish the results.

\section{References}

1. Masingila, J.; Olanoff, D.; Kimani, P. Mathematical knowledge for teaching teachers: Knowledge used and developed by mathematics teachers educators in learning to teach via problem solving. J. Math. Teach. Educ. 2018, 21, 429-450. [CrossRef]

2. Chick, H.; Beswick, K. Teaching teachers to teach Boris: A framework for mathematics teacher educator pedagogical content knowledge. J. Math. Teach. Educ. 2018, 21, 475-499. [CrossRef]

3. Zaslavsky, O.; Leikin, R. Professional development of mathematics teacher educators: Growth through practice. J. Math. Teach. Educ. 2004, 7, 5-32. [CrossRef]

4. Zopf, D. Mathematical Knowledge for Teaching Teachers: The Mathematical Work of and Knowledge Entailed by Teacher Education. Ph.D. Thesis, The University of Michigan, Ann Arbor, MI, USA, 2010.

5. Shulman, L.S. Those who understand: Knowledge growth in teaching. Educ. Res. 1986, 15, 4-14. [CrossRef]

6. Ball, D.L.; Thames, M.H.; Phelps, G. Content knowledge for teaching: What makes it special? J. Teach. Educ. $2008,59,389-407$. [CrossRef]

7. Carrillo, J.; Climent, N.; Montes, M.; Contreras, L.C.; Flores-Medrano, E.; Escudero-Ávila, D.; Vasco-Mora, D.; Rojas, N.; Flores, P.; Aguilar-González, A.; et al. The Mathematics Teacher's Specialised Knowledge (MTSK) model. Res. Math. Educ. 2018, 20 , $236-253$. [CrossRef]

8. Rowland, T.; Turner, F.; Thwaites, A.; Huckstep, P. Developing Primary Mathematics Teaching: Reflecting on Practice with the Knowledge Quartet; Sage: London, UK, 2009; pp. 67-100.

9. Godino, J. Categorías de Análisis de los conocimientos del Profesor de Matemáticas. Rev. Iberoam. Educ. Matemática 2009, 20, 13-31.

10. Smith, K. So, what about the professional development of teacher educators? Eur. J. Teach. Educ. 2003, 26, 201-215. [CrossRef]

11. Montes, M.; Carrillo, J.; Contreras, L.C.; Liñán-García, M.M.; Barrera-Castarnado, V. Estructurando la formación inicial de profesores de matemáticas: Una propuesta desde el modelo MTSK. In Investigación Sobre el Profesor de Matemáticas: Formación, Práctica de Aula, Conocimiento y Competencia Profesional; Badillo, E., Climent, N., Fernández-Verdú, C., González-Astudillo, M.T., Eds.; Ediciones Universidad de Salamanca: Salamanca, Spain, 2019; pp. 157-176.

12. Jaworski, B.; Huang, R. Teachers and didacticians: Key stakeholders in the processes of developing mathematics teaching. ZDM 2014, 46, 173-188. [CrossRef]

13. Beswick, K.; Chapman, O. Mathematics teacher educators' knowledge for teaching. In Proceedings of the 12th International Congress on Mathematics Education, Seoul, Korea, 8-15 July 2012.

14. Ponte, J.P. Mathematics teacher education programs: Practice and research. J. Math. Teach. Educ. 2012, 15, 343-346. [CrossRef]

15. Feiman-Nemser, S. Teacher learning: How do teachers learn to teach? In Handbook of Research on Teacher Education: Enduring Questions in Changing Contexts; Cochran-Smith, M., Feiman-Nemser, S., McIntyre, D.J., Demers, K.E., Eds.; Routledge: New York, NY, USA, 2008; pp. 697-705. 
16. Pascual, M.I.; Montes, M.; Contreras, L.C. Un acercamiento al conocimiento del formador de profesores de matemáticas. In Investigación en Educación Matemática XIX, Proceedings of the XXIII Simposio de la Sociedad Española de Investigación en Educación Matemática, Valladolid, Spain, 7-10 September 2019; Marbán, J.M., Arce, M., Maroto, A., Muñoz-Escolano, J.M., Alsina, A., Eds.; SEIEM: Valladolid, Spain, 2019; pp. 473-482.

17. Grbich, C. New Approaches in Social Research; SAGE: London, UK, 2003.

18. Jaworski, B. Mathematics teaching: What is it? Learn. Math. 1992, 12, 8-14.

19. Escudero-Avila, D.; Montes, M.; Contreras, L.C. What do mathematics teacher educators need to know? Reflections emerging from the content of mathematics teacher education. In The Learning and Development of Mathematics Teacher Educators-International Perspectives and Challenges; Goos, M., Beswick, K., Eds.; Springer: New York, NY, USA, 2020.

20. Olanoff, D. Mathematical Knowledge for Teaching Teachers: The Case of Multiplication and Division of Fractions. Ph.D. Thesis, The University of Syracuse, Syracuse, NY, USA, 2011.

21. Ma, L. Knowing and Teaching Elementary Mathematics: Teachers' Understanding of Fundamental Mathematics in China and the United States; Lawrence Erlbaum: Mahwah, NJ, USA, 1999.

22. Contreras, L.C.; Montes, M.; Muñoz-Catalán, M.C.; Joglar, N. Fundamentos teóricos para conformar un modelo de conocimiento especializado del formador de profesores de matemáticas. In Avances, Utilidades y Retos del Modelo MTSK, Proceedings of the III Jornadas del Seminario de Investigación de Didáctica de la Matemática de la Universidad de Huelva, Huelva, Spain, 17-18 July 2017; Carrillo, J., Contreras, L.C., Eds.; CGSE: Huelva, Spain, 2017; pp. 11-25.

23. Montes, M.; Contreras, L.C. Las creencias de los formadores de profesores que enseñarán matemáticas sobre el contenido y la estructura de la formación inicial de los profesores de secundaria. In Proceedings of the IV Congreso Iberoamericano sobre Conocimiento Especializado del Profesor de Matemáticas, Huelva, Spain, 7-10 September 2019; Carrillo, J., Codes, M., Contreras, L.C., Eds.; Universidad de Huelva Publicaciones: Huelva, Spain, 2019; pp. 14-23.

24. Bassey, M. Case Study Research in Educational Settings; Open University Press: London, UK, 1999.

25. Stake, R. The Art of Case Study Research; Sage: Thousand Oaks, CA, USA, 1995.

26. Stake, R.E. Qualitative Case Studies. In The Sage Handbook of Qualitative Research, 3rd ed.; Denzin, N.K., Lincoln, Y.S., Eds.; Sage Publications: Thousand Oaks, CA, USA, 2005; pp. 166-443.

27. Flick, U. Introducción a la Investigación Cualitativa; Morata: Madrid, Spain, 2007.

28. Baxter, J.A.; Lederman, N.G. Assessment and measurement of pedagogical content knowledge. In Examining Pedagogical Content Knowledge. The Construct and its Implications for Science Education; Gess-Newsome, J., Lederman, N.G., Eds.; Kluwer: Dordrecht, The Netherlands, 2001; pp. 147-161.

29. Perks, P.; Prestage, S. Planning for Teaching. In Mentoring in Mathematics Teaching; Jaworski, B., Watson, A., Eds.; Falmer: London, UK, 1994; pp. 65-82. 